\title{
Obstacles of Planning in domain of Agricultural Farmer Training at the level of agricultural Extension and Training office
}

\author{
Assistant Prof. Dr. Raad Muslim Ismael Al Khazraji \\ Baghdad University/College of Agriculture /Department of Agricultural Extension
}

\begin{abstract}
The current research is to specify systematic description of obstacles of planning in training program domain of agricultural farmer planning at the level of extension and agricultural training office and at the field of Iraq, and to measure level of importance of obstacles planning axes process of farmer agricultural training program in preparation, organization, planning, implementation and evaluation. The research also referred to suggestions of processors and suitable development solutions for the farmer training programs at the level of field in order to preserve and maintain sustainability of agricultural productivity of resources. Data collected from sample 88 of specialist workers in the field of planning and supervision on the implementation of famer training courses via a questionnaire set for this purpose included the first description of the reality of the obstacles by using weighted average, which stands for 2.55 on a three-graded, secondly preparing five-graded scale for the level of importance of the agricultural farmer planning's training obstacles ( 3 domain 7 axes and 38 items). Scale's upper and lower grades ranging 71-178 degrees, with level of importance 's average amounted 146.1 degrees, and standard deviation stands for 12.89 which is located within category of important constraints of planning. It has been prepared a scale of 24 items and 6 axes as to identify order of development proposals at the field. Results of the research has shown that approximately $3 / 2$ of the respondents, and $60 \%$ have proposed to develop agricultural farmer training courses, adopting a two-levels in agricultural farmer training at the level of agricultural fields and this item came first. The current research recommends the necessity of constituting higher committee of training planning at the level of extension directorate and agricultural training; the committee includes experts from Ministry of Agriculture and centers of research and agricultural colleges having the power, guidance and full knowledge of the training plan to confront and resolve impediments of agricultural farmer training as for its importance in modernizing and developing agricultural sector as well as formation of committees or permanent working teams at various field organizational levels of cooperation and coordination as to carry out the fundamental objectives in the development of the agricultural labor force and maintain sustainability of agricultural production resources; besides increasing agricultural production and working on altering currently existing traditional strategies and taking into consideration proposals of development for implementing structural reforms and sustainability of agricultural production resources.
\end{abstract}

Key words: obstacles, planning training. Farmer courses.

\section{Introduction And Research Problem}

Agricultural Extension System have been affected by developments that prevailed over in the world during the last three decades, until becoming before major challenges that could be classified in three levels are " challenges at the global level, challenges on agriculture level and challenges on extension systems[13]. Thusthis requires to move towards structural reforms to cope with rapid advances in transportation and communication networks, vital technology and to meet the change in the cultural phenomena, social, economic, political and administrative on the reality of public and rural life of residents. Besides a change in the agricultural information system to increase the income and preserve sustainability of agricultural resources, and increase production and agricultural productivity in light of dangers facing agriculture and the fragility of environmental systems of small farms for many of the poor farmers who have realized the weakness of extension service ensuing from the decline in the role of government agricultural extension institutions since they do not work as good and appropriate and failing to get to the majority of the rural poor people (especially ruralwomen), with the continuation of weakness in administrative efficiency in the planning and implementation extension programs and training programs. Searching into a complete and sustainable agricultural development has become occupying an important place in developing countries, including Iraq for its role in improving the level of life of the rural people and overcoming underdevelopment and deterioration which Iraq suffers from. The priority of the comprehensive and sustainable agricultural development lies in developing the labor force human resources, thus, the need for trained and educated manpower is continued for moving towards fulfilling food security. This could be done through establishing modern and developed agricultural systems where methods and agricultural technologies are used to achieve an increase in production 
and agricultural productivity in an effort to reach self-sufficiency and in order that agriculture does not become a burden on the national economy

Hence, the role of suitable scientific planning to exploit the available resources, it also helps give a huge importance to the planning of training in the field of agriculture for being one of the most important causes to improve and raise agricultural production through the development of human resources, and other manpower in agriculture by directing behaviors in knowledge, skills and trends working on raising its capacity to enable it to perform its work efficiently to modernize agriculture.

The importance of planning in the field of farmer training or the so-called planning of training has been considered one of the important areas between the planning and training since the both elements contribute to proper development of human element working in the agriculture[1]. Thus, the process of planning aimed at mobilizing, coordinating and directing resources, energies and manpower available (at present and future)as to achieve economic, social and cultural development, while the process of farmer training is an organized and purposed process, aiming at acquiring farmer trainees with knowledge, skills and abilities for improving the current and future performance. [2]

The process of planning the training is considered a comprehensive and continuous process, aiming at achieving goals and training activities in order to achieve optimal use of resources and facilities available for training and preparation programs; besides, providing training supplies and determining when to use them in a way suitable with nature of the needs. Working to create the physical, financial and artistic capabilities to be mobilized towards the achievement of what is required [3]. The fact that the former fields when planning training are theoretical and academic matters and when being subjected to the application at the field level, they confront a lot of obstacles and difficulties. When application of farmer training's programs continues, a lot of problems would be appeared that must be addressed and overcome. Sub- Obstacles and problems would be resulted from the former theoretical subjects that required to be examined, analyzed and classified to find out solutions and to overcome negative consequences resulting thereform,moving toward deepening into applying positive results of the principles and foundations of farmer training along with its training programs. For planning for any educated or extensive or training activity, there should be a model to follow to trace its steps in a specific, precise and organized manner to facilitate its implementation and to evaluate and resolve the obstacles that hinder their effective application[4]. WE also think that are other classifications stand for obstacles to training planning that could be distributed according to its primary sources and to include: regulatory,structural, administrative, educational, ad valorem, financial, psychological and social constrains), or to be distributed by stages and include (to recognize thetraining need, preparing training means, training of trainers, training methods, and follow-up and rectification of training). (Tem.w) has confirmed the importance of developing the method of any training plan (as being as a process used to identify training needs, and identify training goals), and the development of the curriculum; besides, the selection of training methods ,assistant resources development and design of curriculum which are considered the only way to train the designer, so it can handle the obstacles of its build with high efficiency [5].

The search in the changing strategies of how the traditional methods are changed in planning, implementation and evaluation of extension and training programs in general and agricultural farmer training programs in particularity. For improving the quality of the plans and programs, it should elevate skills of planners and other farmers workers in assimilating the implications relating to the resolution of obstacles and agricultural farmer training problems and that contribute to the growth and improvement of rural life and agricultural production. It is worthy to be mentioning here that strategic management can modify extension regulation trends and makes it more appropriate with the strategic environment and increase the value of the organization from the beneficiaries' viewpoints (farmers) through improving former levels of performance by using strategic planning analysis using or the so-called internal analysis by examining the strengths and weaknesses and external analysis by external environment analysis of the opportunities and meet threats [12].The Classification of obstacles of training planning in the current research takes into consideration the shape , organization ,stages and steps as that models of planning a training in " Hudson,AlSilmi ,Abdul Ghaffar, Boyel[6]. When planning the training of agricultural farmer programs e to include three stages, planning, implementation and evaluation , taking into account the detailed steps with specific degrees, with the direction of taking the opinion of Dewey into consideration the importance of the principle of education based on the experience, which includes real-life experience of others [7]. Identifying and describing the obstacles and indicating its importance would actually help address and resolve some of the problems of agricultural extension in terms of its availability andimportance of its impact along with methods of developing it [15].

As studies show that agricultural development programs in Iraq faces significant challenges for the lack of trained manpower participatingin agricultural projects or managing farms andfields efficiently [8]. The report of the Arab Labor Organization, which was prepared for manpower in agriculture in the Arab countries in 1970 referred to deterioration of labor force's contribution into modernizing agriculture . Depending on importing equipment, machinery, fertilizer, seeds and other agricultural technologies are not sufficient to bring about change and modernization of the agriculture sector, but rather requiresa concern over training farmers

DOI: $10.9790 / 2380-1004020110 \quad$ www.iosrjournals.org $\quad 2 \mid$ Page


and other labor force in agriculture in various agricultural activities and areas [9]. The researcher seesthat the deterioration of agriculture has been increased, especially after long years of war, siege and unsuitable conditions since 2003 up to the present time with persistent drought and spread of desertification in agrarians and reduced implanted lands along with the increase of population and others. All these factors lead to declineagriculture sector's contribution in the gross national product, which requires searching in obstaclesthat faced the agricultural farmer training and its role in the provision of rural residents - related rained manpower in agriculture to improve their role in economic and social life in order to achieve justice and to achieve sustainable development through directing services towards all producers in the countryside [10]. Most importantly, indications issued by extension and training office and confirmed the decline of importance and role of the agricultural farmer training as development programs have become not receiving any importance from concerned bodies and other concerned offices as well as beneficiaries of farmers. Indications of annual plans [11] especially at the level of field have become just merely titles for training courses agricultural without giving attention to the scientific steps and process of training planning ; besides, these training programs facing obstacles countlessly would ultimately lead to reset and minimize the role of this vital activity in life of the rural residents and diagnose problems which is represented as a contributor role toward reforms in the extension domain. Hence, fragmenting obstacles and problems by steps, stages and priorities would give greater importance to place successful solutions to them, according to the resources and possibilities available. ? Thus, it does allowplacingreforms in the agricultural training system and resources based on available resources. The research has thus come to answer the following inquiries:

1. Conceptualizing intellectually and practically to describe the reality obstacle of planning agricultural farmer training's as a product and process.

2.Identifying the level of obstacle importance of the planning training agricultural farmer program.

3. Specifying the level ofobstacle importance of planning training the agriculturalfarmer programs in planning, implementation and evaluation.

4. Identifying some proposals of development for planning training agricultural farmer curses on the level of extension and training office as well as on the level of field.

\section{Research Hypothesis} caused in:

The agricultural farmer training 's programs face manyaccumulated obstacles and problems which

Lacking understanding in planning of agriculturalfarmer training as a product and process and the existence of systematic classification allows placing reforms for systems of agricultural farmer training.

\section{Method OF Research}

Research Methodology: The researcher usedfield survey in achieving the goals of current research because it is appropriate to get data about impediments of agricultural farmer training 's planning which is ensued from descriptive of social research.

\section{Society and the research sample}

The research's society includes technicians agriculture staff and extension working in the field of farmer agricultural training planning in the agricultural extension and training director in Iraq, relevant centers and extension farms in the governorates. they have numbered 104 ; it has been selected a random sample proportionally by $80 \%$ of those working in sections and farmsextension model; the size of the sample size was 88 researchers distributed in various locations of extension and agricultural training office as in the table (1)

Table 1: the distribution of the society and sample of research

\begin{tabular}{|l|l|l|l|}
\hline Worksite & Society & Sample & $\%$ \\
\hline 1.Head of Extension Depart. & 13 & 13 & 15 \\
\hline 2.Head of Extensioncenter & 13 & 13 & 15 \\
\hline 3.Head of Extension section & 48 & 38 & 43 \\
\hline $\begin{array}{l}\text { 4.Head of farm extensionmodel } \\
\text { farming }\end{array}$ & 30 & 24 & 27 \\
\hline Total & 104 & 88 & 100 \\
\hline
\end{tabular}

Some aspects of sample of research:

a- Scientific qualification

The table No. (2) shows distribution of sample according to scientific qualification, , thus $78 \%$ of them are holder of bachelor degrees and that $7 \%$ of them are holders of agriculture secondary certificate. 
Obstacles of Planning in domain of Agricultural Farmer Training at the level of ...

Table 2: the distribution of the respondents according to scientific qualifications

\begin{tabular}{|l|l|l|}
\hline Scientific qualifications & Numbers & $\%$ \\
\hline 1.Paultry doctor & 1 & 1 \\
\hline 2.Assistant engineer of agriculture & 68 & 77 \\
\hline 3.Diploma & 13 & 15 \\
\hline 4.Agriculture secondary certificate & 6 & 7 \\
\hline Total & 88 & 100 \\
\hline
\end{tabular}

B) Years of service

Table 3 shows the distribution of respondents by years of service in the agricultural work in the field of agricultural farmer training and $43 \%$ of the sample are new employees and those with service of less than 5 years and $17 \%$ of them have a service more than 21 years

Table 3: the distribution of the respondents according to the service in the field of agricultural farmer training

\begin{tabular}{|l|l|l|l|}
\hline Serial & Years of services & Number & $\%$ \\
\hline 1 & $1-5$ & 38 & 43 \\
\hline 2 & $6-10$ & 18 & 20 \\
\hline 3 & $11-15$ & 12 & 14 \\
\hline 4 & $16-20$ & 5 & 6 \\
\hline 5 & More than 21 & 15 & 17 \\
\hline Total & & 88 & 100 \\
\hline
\end{tabular}

\section{C- Supervision and agricultural Farmer training}

Table 4 shows the distribution of the respondents according to supervision on the implementation of the agriculturalfarmer training courses, and $56 \%$ of the sample fall within the category of supervision, and that $19 \%$ of them does not have any supervision or farmertraining.

Table 4: Distribution of the respondents according to supervision on the implementation of the agricultural farmer courses

\begin{tabular}{|l|l|l|}
\hline Supervision and courses implementation category & Number & $\%$ \\
\hline 1. Much & 49 & 56 \\
\hline 2.Rarely & 22 & 25 \\
\hline 3.None & 17 & 19 \\
\hline Total & 88 & 100 \\
\hline
\end{tabular}

\section{Tool of data collection:}

It has been used the questionnaire to collect data from respondents, the questionnaire is considered as a method for data-collection and most effective means. The questionnaire was in parts and forms : The first part included a set of general questions concerning the respondents while the second parthas identified description of the reality of fields and axes obstacles to agricultural farmer training planning and has been used weighted averageafter it was given three degrees $(3,2,1)$ to the level of a little , medium, and much. . Second, determining the levelof importance of farmer training planning's obstaclesand has been measured with fifth -graded scale for phrases (very important, important, medium importance, little important, a very little important) and having given weights 5,4,3,2,1 respectively; it has included 3 areas and 7 axes and 38 items as theoretical and practical view for the process. The third part included suggestions of development for 6 axes and every axil includes four alternatives and could be chosen one or more of these alternatives.

\section{Consistency and Validity:}

Consistency and validity have been examined for classifying level of importance of the obstacles of agricultural farmer training planning and suggestions of development using Alvkrbach equivalent's equation reached to $0.969,0.94$, and was also used SPSS in the analysis of research data, as well as used statistical methods, repetition, percentage ,standard deviation and weighted average.

\section{Results And Discussion}

4.1. Identify and describe the reality obstacle of planning training thefarmer programs

It has been identified systematical method to describe the reality ofthe farmer training obstaclesfor items and subjects mentioned.It has been described the presence of obstacles and availabilityAccordingto requirements of research for accessing to the distinction between the cases on basis of three areas which are: obstaclesof planning process, obstacles of implementation process, and obstaclesof evaluation process. The researcher has used weighted average (weighted) in accordance with items according to three levels little, medium, and much 1,2,3, respectively, as shown in Table (5) 
Obstacles of Planning in domain of Agricultural Farmer Training at the level of ...

Table 5: distribution of the respondents according to the reality of obstacles farmer planning training program's.

\begin{tabular}{|c|c|c|c|c|c|c|c|c|}
\hline Fields Category & \multicolumn{2}{|c|}{ Little } & \multicolumn{2}{|c|}{ Medium } & \multicolumn{2}{|c|}{ Much } & Weigh Average & Arrangement \\
\hline 1.Obstacles of Planning & Nr. & Ratio & Nr. & Ratio & $\mathrm{Nr}$ & Ratio & & \\
\hline 2.Obstacles of & 7 & 10.0 & 15 & 17.0 & 66 & $\begin{array}{l}75.0 \\
75.4\end{array}$ & 2.78 & 1 \\
\hline Implementation process & & & & & & & & \\
\hline $\begin{array}{l}\text { 3.Obstacles of Evaluation } \\
\text { process }\end{array}$ & 10 & 11.4 & 21 & 23.8 & 57 & 64.8 & 2.53 & 2 \\
\hline Average & 11 & 13.0 & 18 & 20.0 & 59 & 67.0 & 2.55 & \\
\hline
\end{tabular}

The table No. 5 shows that the weigh average for describing the reality of the agricultural farmer training planning 's obstacles amounted 2.55 degree and the average of all fields of agricultural farmer training planning in ( planning, implementation and evaluation) amounted 2 degree. More than $67 \%$ of researchers have indicated that there are huge obstacles facing agricultural farmer training planning programs; besides the obstacles of agricultural farmer training planning came in the first rank with weighing average (2.78) degree. This is conforming to the hypothesis of research by existing much obstacles facing agricultural farmer training planning.

All weighing rates of describing the reality of obstacles exceed in its values $81 \%$ of high numeric degree amounted 3 degree for nor existing trusted and continued permanent work procedures from those working (sample of research) in the agricultural extension director and that enable them to get back to them when placing the annual plans or training programs. The continuation of its existence and lacking of sufficient development lead to weaken the efficacy of the training programs along with its plans to improve the cognition awareness of the farmers and to adopt modern agriculture techniques. This ultimately would reflect on the agricultural production.

\subsection{Specifying level of obstacle importance of agricultural farmer training planning's obstacles:}

The results of research have indicated that the level of agricultural farmer training planning's obstacles ranged between 38-190 degree and the categories distributed on three levels ( of little importance , medium importance, important ); its degree amounted 71-106, 107-142, 143-178) .

Table 6: Distribution of the respondents according to the level of agricultural farmer training planning's obstacles fields.

\begin{tabular}{|l|l|l|l|l|l|l|l|l|}
\hline Areas Category & \multicolumn{2}{l|}{ Little 106-70 } & \multicolumn{2}{l|}{$\begin{array}{l}\text { Medium /107- } \\
142\end{array}$} & \multicolumn{2}{l|}{ Much 143-178 } & Weigh Average & Arrangement \\
\hline $\begin{array}{l}\text { 1.Obstacles of Planning } \\
\text { process }\end{array}$ & $\begin{array}{l}\text { Nr. } \\
14\end{array}$ & $\begin{array}{l}\text { Ratio } \\
\text { 2.Obstacles }\end{array}$ & $\begin{array}{l}\text { Nr. } \\
19\end{array}$ & $\begin{array}{l}\text { Ratio } \\
22\end{array}$ & $\begin{array}{l}\text { Nr. } \\
55\end{array}$ & $\begin{array}{l}\text { Ratio } \\
63\end{array}$ & 141.9 & 3 \\
$\begin{array}{l}\text { Implementation process of } \\
\text { 3.Obstacles of Evaluation } \\
\text { process }\end{array}$ & 5 & 6 & 15 & 17 & 68 & 77 & 150.8 & 1 \\
\hline Average & 9 & 10 & 20 & 23 & 59 & 67 & 2 \\
\hline
\end{tabular}

Table 6 shows thelevel of importance of obstacles classifications' categories facing the agricultural training planning process amounted 146.1 degrees and standard deviation of 12.89 degrees and it is located within an important category .About $11 \%$ of the sample is located within the level of minor importance, and that the proportion of $69 \%$ of the sample came within an important category. It is concluded that more than $3 / 4$ of respondents have classified obstacles of agriculturalfarmer planning training that they are located between medium importance and importance with ratio $89 \%$. The arrangement of obstacles of implementation process of agricultural famer training programs came with the first rank with average 150.8 degrees and is located within importance category, while obstacles of evaluation process came in second place and it is located within importance category and the average of the level of significance was 145.6 degrees ; obstacles of planning process came in third place with average 141.9 degrees, which is rarely fallen within the category of important . The researcher believes that the hypothesis research of reason for this is due to the weakness of the operational theoretical and practical aspects offarmer agricultural training process as a producer and operations directed towards contribution into improving agricultural production and development and sustainability of resources, besides weakness resulted by the assimilation of extensive managements at the level of the organizational aspects that concerned over agricultural farmer training planning toward the importance of forming a vision and a message to the extension and agricultural training director in this field.Particularly this activity is introduced to the rural and agricultural areas on level of provinces and districts .

4.3.Identifying level of importance of the farmer training planning obstacles fields and includes

A) Determining the level of importance of the obstacles facing the process of farmer training planning. 
Results of the research have showed level of importance of obstacles that faced the agricultural training planning process, it's showed importance of the constraints facedthe farmer training process ranged between 3993 degrees distributed to three levels of categories are (a few importance, medium importance, importance ).

Table 7: Distribution of the respondents according to the level of importance facing the agricultural farmer training planning process:

\begin{tabular}{|c|c|c|c|c|c|c|c|c|}
\hline \multirow{2}{*}{$\begin{array}{l}\text { Areas Category } \\
\text { 1. obstacles facing the } \\
\text { general frame work } \\
\text { agricultural farmer training } \\
\text { planning process }\end{array}$} & \multicolumn{2}{|c|}{ Little 56-38 } & \multicolumn{2}{|c|}{ Medium /57-75 } & \multicolumn{2}{|c|}{ Much 76-93 } & \multirow{2}{*}{$\begin{array}{l}\begin{array}{l}\text { Weigh Average of } \\
\text { importance }\end{array} \\
73.5\end{array}$} & \multirow{2}{*}{$\begin{array}{l}\text { Arrangement } \\
2\end{array}$} \\
\hline & $\begin{array}{l}\text { Nr. } \\
17\end{array}$ & $\begin{array}{l}\text { Ratio } \\
19\end{array}$ & $\begin{array}{l}\text { Nr. } \\
18\end{array}$ & $\begin{array}{l}\text { Ratio } \\
21\end{array}$ & $\begin{array}{l}\text { Nr. } \\
\mathbf{5 3}\end{array}$ & $\begin{array}{l}\text { Ratio } \\
60\end{array}$ & & \\
\hline $\begin{array}{l}\text { 2.Obstacles facing the } \\
\text { organization of agricultural } \\
\text { farmer training planning } \\
\text { process. } \\
\text { 3.Obstacles facing actual } \\
\text { planning of agricultural } \\
\text { farmer training process. }\end{array}$ & 16 & 18 & 20 & 23 & 52 & 59 & 76.3 & 1 \\
\hline G. Average & 14 & 15 & 19 & 22 & 55 & 63 & 74.4 & 8.1 S.D \\
\hline
\end{tabular}

Table no. 7 indicates that the rate of level of significanceof obstacles' categories and problems ( appeared by starting the planning process for farmer training) amounted 74.4 degree, standard deviation 8.1 degree getting close to category of importance., ratio $15 \%$ of the sample lies within category of little importance, $63 \%$ of the sample came within category of importance. It has been concluded that more than $3 / 4$ of respondents have classified obstacles of farmer training planning that lie within category of medium importance and importance with ratio $85 \%$. Arrangement of obstacles facing agricultural farmer training planning process came in the first rank with average 76.3 degree and it is located within category of importance; whereas obstacles facing the general frame work and organization obstacle of agricultural farmer training planning process came in second and third ranks with level of importance amounted 73.5, 73.4 degree respectively, the latter both get close to category of importance. The researcher thinks reasons behind that lay in the weakness of efficiency of the concerned people working in agricultural and extension director on how to specify training needs for the farmer trainees for being considered the scientific basis by which it could measure efficiency of agricultural farmer training results. Besides, the deterioration of awareness of obstacles concerning over philosophical and theoretical sides along with the general goals linking to the needs of rural society. After long years of suffer of extension apparatus from human resources and financial capabilities' rarity, that there is kind of concern over providing these capabilities, but they are far-fetched fulfilled to achieve desired changes in agricultural production types.

B) Determining the level of importance of the obstacles and problems facing the implementation process of farmer agricultural training planningprograms.

Results of the research show that the level of importance of the obstacles facing the processes of implementation of agricultural programshave ranged between 17-46 Degree; it has been distributed the categories on three levels, namely, (of little importance, medium importance, importance ).

Table 8: Distribution of the respondents according to the level of importance of obstacles facing the implementation of farmer training planning courses:

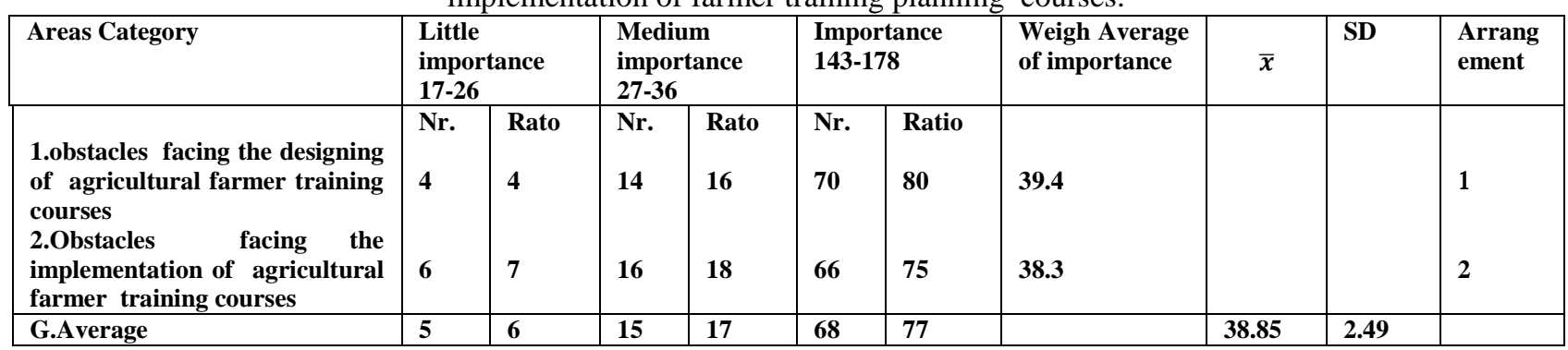

Table No. 8 indicates that the average of level of significance of obstacles' and problems' classification categories facing the process of implementation of training courses programs amounted 38.85 degree , standard deviation 2.49 degree getting close to category of importance., $6 \%$ of the sample lies within category of little importance , $77 \%$ of the sample came within category of importance. It has been concluded that most respondents haveindicated that obstacles of training courses implementation lie within category of medium importance and importance with ratio $92 \%$. Category of obstacles facing designing of agricultural

DOI: $10.9790 / 2380-1004020110 \quad$ www.iosrjournals.org $\quad 6 \mid$ Page


farmer training planning process came in the first rank with average 39.4 degree and it is located within category of importance; whereas obstacles facing the implementation of agricultural farmer training courses came in second rank with level of importance amounted 38.3 degree (it is located within category of importance). The researcher thinks that axes of training courses implementation process have been considered the basis of obstacles and problems facing this activity in training and extension director . Reasons behind that lay in the weakness of efficiency of the concerned people working in agricultural and extensive director on how to actually design training courses texts on bases of field and practical domain and because of lacking of knowledge, information and artistic and cognitive skills concerned over modern agricultural techniques and scientific recommendations; besides, pacing not the developments on how to design training scientific texts. Reasons might be fallen within the weakness of entailing the scientific and academic experiences in research centers, universities and agricultural colleges, as there is no transparent distinction between the implementation of training courses programs and local forums activities. Moreover ,the reality indicates that the course has become part of extensive farmer forum and resulted into straying this vital field in the extension director and rural people ( the beneficiaries).

C) Determining the level of importance of the obstacles of farmer agricultural training planning programsevaluation .

Results of the research have indicated that the level of importance of the obstacles facing the processes ofevaluation of farmer training programshave ranged between 39-16 Degree; it has been distributed the categories on three levels, namely, (of little importance, medium importance, importance ).

Table 9: Distribution of the respondents according to the level of importance of obstacles facing the process of farmer training planning programs evaluation,

\begin{tabular}{|c|c|c|c|c|c|c|c|c|c|c|}
\hline Area Category & $\begin{array}{l}\text { Littl } \\
\text { imp } \\
16-2\end{array}$ & & $\begin{array}{l}\text { Med } \\
\text { impc } \\
24-3\end{array}$ & & Imp & ance & $\begin{array}{l}\text { Weigh } \\
\text { Average of } \\
\text { importance }\end{array}$ & $\mathbf{X}$ & SD & $\begin{array}{l}\text { Arrangeme } \\
\text { nt }\end{array}$ \\
\hline $\begin{array}{l}\text { 1.obstacles facingstructure } \\
\text { and agricultural farmer training } \\
\text { evaluation. } \\
\text { 2.Obstacles } \\
\text { facingevaluationand trainees } \\
\text { and training of agricultural } \\
\text { farmer. } \\
\text { G.Average }\end{array}$ & $\begin{array}{l}\text { Nr. } \\
8\end{array}$ & $\begin{array}{l}\text { Rato } \\
9\end{array}$ & $\begin{array}{l}\text { Nr. } \\
22\end{array}$ & $\begin{array}{l}\text { Rato } \\
25\end{array}$ & $\begin{array}{l}\text { Nr. } \\
59\end{array}$ & $\begin{array}{l}\text { Ratio } \\
66\end{array}$ & 32.5 & 32.3 & 22.38 & 2 \\
\hline
\end{tabular}

Table No. 9 indicates that the average of level of significance of obstacles and problems of agricultural farmer training courses amounted 32.3 degree, standard deviation 2.38 degree getting close to category of importance. , $10 \%$ of the sample lies within category of little importance, $67 \%$ of the sample came within category of importance. It has been concluded that most respondents have classified obstacles of agricultural farmer training rectification courses that are located within category of medium importance and importance with ratio $90 \%$. Category of obstacles facing rectification of agricultural farmer training planning process came in the first rank with average 32.5 degree and it is located within category of importance; whereas obstacles facing the process of agricultural farmer training rectification came in second rank with level of importance amounted 32 degree (it is located within category of importance). The researcher thinks that reasons lying behind that related to existing administrative structure that undertakes responsibility of rectifying process of agricultural farmer training programs to know results of training and level of achieving desired goals and to get benefit thereof . besides, its reflection on developing agricultural production and sustaining its resources. The training process has achieved suitable designs of methods and necessities and results of research indicated to the complete inability of this activity to achieve its goals and tasks.

5-Knowing some suggestions to develop the agricultural farmer training at the level training and extension director, and at the fields level.

a- Developmental suggestions on how to prepare activities and agricultural farmer training programs.

This part of the research deals with suggestions aiming at developing courses and training programs submitted to the farmer at the level of field. Hereunder some suggestions to develop agricultural farmer training on how to prepare programs and activities of farmer training to suit definite level of technical and educational levels, and could be chosen one or more of theses alternatives. 
Obstacles of Planning in domain of Agricultural Farmer Training at the level of ...

Table10: Distribution of the respondents according to how to prepare activities and programs of farmer training

\begin{tabular}{|l|l|l|l|}
\hline Suggestions of development & $\mathrm{Nr}$. & $\%$ & Level of importance \\
\hline $\begin{array}{l}\text { 1.By depending on two levels of training, the first } \\
\text { one is for the farmers having capabilities of } \\
\text { applying agricultural techniques and the second } \\
\text { is for farmers having not capabilities }\end{array}$ & 56 & $60 \%$ & 1 \\
$\begin{array}{l}\text { 2.By depending on two levels of qualification , } \\
\text { the first one for the farmers having completed } \\
\text { primary school and the second one is for those } \\
\text { having not completed the primary school. }\end{array}$ & 18 & 19 & 2 \\
$\begin{array}{l}\text { 3-Unnecessary to depend on former limits. } \\
\text { 4-other Little awareness of farmers }\end{array}$ & 15 & & \\
\hline TOTAL & 4 & 15 & 3 \\
\hline
\end{tabular}

The table No. 10concluded that about $2 / 3$ of respondents with ratio $60 \%$ have indicated to the dependence of two levels of agricultural farmer training, the first one is for the farmers having capabilities of applying agricultural techniques and the second is for farmers having not capabilities/. The importance of this item came in the first rank. And about $4 \%$ of them have indicated to the little awareness of the farmers and it came in the last rank .

b-developmental suggestions on how to design farmer training at the level of field.

Hereunder some suggestions to develop agricultural farmer training on how to prepare programs and activities of farmer training and could choose one alternative or more of suitable alternatives for application as that appeared in the table No. 12.

Table 11:Distribution of the respondents to design farmer training at the level of field.

\begin{tabular}{|c|l|c|c|c|}
\hline Serial & Suggestions of development & Nr. & $\%$ & Importance arrangement \\
\hline 1. & $\begin{array}{l}\text { The main activity lies within the } \\
\text { training programs ( the training of } \\
\text { farmers on accurate remarks and } \\
\text { corrections instead of lectures. }\end{array}$ & 48 & 43 & 2 \\
\hline 2. & $\begin{array}{l}\text { The main activity lies within the } \\
\text { training programs ( the application of } \\
\text { skills and modern techniques on the } \\
\text { field ) }\end{array}$ & 51 & 46 & 1 \\
\hline 3. & $\begin{array}{l}\text { The main activity lies in the specialists } \\
\text { lecture }\end{array}$ & 10 & 9 & 3 \\
\hline 4. & $\begin{array}{l}\text { (other than that the diminishing of } \\
\text { participants owing to weak capabilities } \\
\text { and difficulty of transport to locations } \\
\text { of training. }\end{array}$ & 2 & 2 & 4 \\
\hline & & 111 & 100 & \\
\hline
\end{tabular}

It has been concluded that less of 112 of responds with ratio $46 \%$ have indicated to the application of skills and modern technique on the field on training programs.

C-Developmental suggestions on how to improve environment of agricultural farmer training and arrangement of importance.

Hereunder some suggestions on how to develop the environment of agricultural farmer training. it could choose one alternative or more than that of suitable alternatives .

Table 12:shows distribution of respondents according to how to improve environment of agricultural farmer training and arrangement of importance.

\begin{tabular}{|c|l|c|c|c|}
\hline Serial & \multicolumn{1}{|c|}{ Suggestions of development } & Nr. & Importance arrangement \\
\hline 1. & $\begin{array}{l}\text { By depending on intensive field training in one day in the field of farmer } \\
\text { it includes extension forums and practical applications and } \\
\text { observations) }\end{array}$ & 35 & 32 \\
\hline 2. & $\begin{array}{l}\text { By the method of organizing field tour to some fields of farmers or } \\
\text { research areas }\end{array}$ & 61 & 55 & 8 \\
\hline 3. & Self- Efficiency in the training and extension offices & 8 & 3 \\
\hline 4. & $\begin{array}{l}\text { ( other than that the weakness of educational office and control of } \\
\text { trainees }\end{array}$ & 6 & 5 \\
\hline Total & & 110 & 100 \\
\hline
\end{tabular}

It has been concluded that more than $1 / 2$ of respondents with ratio $55 \%$ have suggested that the development of the agricultural farmer training environment by organizing field visits to some field of farmers . this item 
came in the first rank, while $5 \%$ of them have suggested the development of efficiency of senior supervisors on farmer training courses to control on trained groups involved in it.

d-Developmental Suggestions on how to suit the training needs for the farmer and agricultural farmer training programs.

Hereunder some suggestions on how to develop the suitability of training needs of the farmers and programs and activities of agricultural farmer. It could choose one alternative or more than that of suitable alternatives as that mentioned in table No. 13.

Table 13: shows distribution of respondents according to how to the suitability of training needs and training

\begin{tabular}{|c|c|c|c|c|}
\hline Serial & $\begin{array}{c}\text { Suggestions of } \\
\text { development }\end{array}$ & $\mathrm{Nr}$. & $\%$ & Importance arrangement \\
\hline 1. & $\begin{array}{l}\text { Inquiring from the } \\
\text { farmer organizations } \\
\text { about the training needs } \\
\text { of farmers }\end{array}$ & 26 & 24 & 3 \\
\hline 2. & $\begin{array}{l}\text { The farmer asks the } \\
\text { participant's about the } \\
\text { farmer's training needs. }\end{array}$ & 41 & 39 & 1 \\
\hline 3. & $\begin{array}{l}\text { The agricultural } \\
\text { supervisor asks about } \\
\text { training needs of farmers }\end{array}$ & 38 & 35 & 2 \\
\hline 4. & $\begin{array}{l}\text { (other than that taking } \\
\text { the opinion of senior } \\
\text { officials and tribes chiefs } \\
\text { ) }\end{array}$ & 3 & 2 & 4 \\
\hline Total & & 108 & 100 & \\
\hline
\end{tabular}

It has been concluded that more than $1 / 3$ of respondents with ratio $39 \%$ have suggested that the development of the suitability of training needs of farmers and programs and activities of training carried out via the inquiry of the farmers themselves about the training needs. This item came in the first rank, while $2 \%$ have suggested inquiries of tribes chiefs.

d-Developmental Suggestions on how to develop extension individuals and employees in field of modern agricultural techniques.

Hereunder some suggestions on how to develop or re-arrange extension individuals and employees who are responsible for the agricultural farmer training on how to transport modern agricultural techniques. It could choose one alternative or more than that of suitable alternatives as that mentioned in table No. 14

Table 14: shows distribution of respondents according to how to train and develop the extension employees in field of transferring agricultural techniques and arrangement of importance.

\begin{tabular}{|c|c|c|c|c|}
\hline Serial & Suggestions of development & Nr. & $\%$ & Importance arrangement \\
\hline 1. & $\begin{array}{l}\text { By holding practical discussion in } \\
\text { training and its methods. }\end{array}$ & 24 & 22 & $\mathbf{3}$ \\
\hline 2. & $\begin{array}{l}\text { By holding annual training courses for } \\
\text { those performing farmer training }\end{array}$ & 55 & 51 & 1 \\
\hline 3. & $\begin{array}{l}\text { By preparing leaflets or publication } \\
\text { about training and its methods and that } \\
\text { leaflets distributed on all training } \\
\text { centers and extension offices }\end{array}$ & 25 & 24 & 2 \\
\hline 4. & ( other than that raining abroad ) & 3 & 3 & 4 \\
\hline Total & & 107 & 100 & \\
\hline
\end{tabular}

respondents with ratio $51 \%$ have suggested the development of the agricultural employees ( of supervisors ) in field of transferring modern techniques via holding annual training courses over training and its methods. This item came in the first rank, while 3\% of them have suggested that the training should be held abroad. d-Developmental Suggestions on rectifying the activity of agricultural training. Hereunder some suggestions on how to develop the process of rectification and its stages on the agricultural farmer training. It could choose one alternative or more than that of suitable alternatives as that mentioned in table No. 15 . 
Obstacles of Planning in domain of Agricultural Farmer Training at the level of ...

Table 15: shows the development of rectification process and its effective elements on agricultural farmer training activity.

\begin{tabular}{|c|l|c|c|c|}
\hline Serial & \multicolumn{1}{|c|}{ Suggestions of development } & Nr. & $\%$ & Importance arrangement \\
\hline 1. & $\begin{array}{l}\text { By observation of the organization based } \\
\text { on files previously prepared by the head } \\
\text { of the farmer center. }\end{array}$ & 30 & 28 \\
\hline 2. & $\begin{array}{l}\text { By the inquiry of the farmer according to } \\
\text { the file prepared by the extension office } \\
\text { and agricultural training }\end{array}$ & 40 & 36 & 1 \\
\hline 3. & $\begin{array}{l}\text { BY having the extension employee get } \\
\text { close to the training activity }\end{array}$ & 37 & 33 & 2 \\
\hline 4. & $\begin{array}{l}\text { (other than that, doing not rectification } \\
\text { process) }\end{array}$ & 3 & 3 & 4 \\
\hline Total & & 107 & 100 & \\
\hline
\end{tabular}

It has been concluded that more than $1 / 3$ of respondents with ratio $36 \%$ have suggested the development of rectification process along with its effective elements on farmer agricultural training according to files prepared previously by the extension office and agricultural. This item came in the first rank, while $3 \%$ of them have suggested not to carry out the rectification process for its difficulty .

\section{Conclusions And Recommendations:}

Based on achieved results that there is a set of important obstacles having an effect on programs of agricultural farmer training courses. Reasons of such obstacles lie in the weakness of extension offices and training centers in the governorates as to improve, change and develop agricultural human capabilities working in the agricultural fields; besides, weakness in level of extension employees and technical supervisors on the programs and activities of training and its methods.

Thus, the researcher has recommended the necessity of forming high committee ( at the level of agricultural training and extension office ) includes experts from ministry of agriculture and related research centers of college of agriculture; they have experience and knowledge to face obstacles of agricultural farmer training and programs application; besides, specifying goals, policies and procedures of farmer agricultural training activity. Constituting permanent committees and teams in different levels of coordination as to achieve the goals and to sustain the productive resources available when planning farmer training programs. This contribute into carrying out increase in production and agricultural production, taking into consideration proposals of development mentioned in the research and changes in the currently followed-up traditional strategies , and trend to wards agricultural vocational training and professional condenser and enable farmers to become coach of others and get away the document to indoctrination training .

\section{Reference}

[1] Al-khazragi, Raad.M.I. 2015. Planning for training course to diffused date palms produced by tissue culture technique. Iraqi J.Agric.Res.Vol.20 No.1 pp.179-191.

[2] Abd.Alwahip,M.1981.Training and development .general instate for management. Al-riyath.pp23-38 .

[3] Ali,A and Saad,A.1974.training needs . theAOMS,journal. Atlas for public-Egypt.p.9.

[4] Ismail,R.M.2013. thestste of extension planning process in Baghdad agricultural directorate . The Iraqi .J.Sci:44(6):719-728.

[5] Tim,W.1993.planning for effective training .FAO.Rome.p.62.

[6] Al-Hamdiny, Amiad.1984.Asuggested sample for planning of Training of works at the ministry of agriculture and agrarian reform, MSc. Thesis college of agriculture Baghdad university , p.p.54-68.

[7] Dewey,John.2007,Experience and education, published by Arrangement with kappa delta, Newyork.p.89.

[8] Ministry of agriculture . 2010 work paper for ministry of agriculture to make Iraq green oasis. P.15.

[9] State board of agricultural extension and training . 1985.Imporatanees of Training for developed agriculture sector Baghdad.pp.10-11.

[10] Arabic development originstion.2001. study of Improving the agricultural extension in Arabic homeland. Khartoum.pp93-97.

[11] State board of agricultural extension and training . 2013. Extension and training planning. Follow up and planning dept-n.224

[12] Auawth.M.Ahmad.2000.strategic Management. Universal press Eygpet.p3-9.

[13] Qamr.M.kalim .2005.inovation system of national agricultural extension . FAO.Rome.p2.

[14] Alicia Gonzalez.2011 .Education for rural development . Adult Education and development ,J.N.7.P29 .Germany .

[15] Aezow. D.N. 2005 .The views of the agricultural Extension workers employed of extension problems work in Iraq in terms of size and Importance .phD. thesis ,college of aric-and forestry, Mosul , u.v.p17 . 